\title{
Effects of moisture on the mechanical properties of glass fibre reinforced vinylester resin composites
}

\author{
RITA ROY, B K SARKAR* and N R BOSE ${ }^{\dagger}$ \\ Department of Materials Science, Indian Association for the Cultivation of Science, Calcutta 700 032, India \\ Central Glass and Ceramic Research Institute, Calcutta 700 032, India
}

MS received 15 April 2000; revised 6 November 2000

\begin{abstract}
Glass fibre reinforced vinylester resin composites incorporating varying amounts of fibres (63.5, $55.75,48.48,38.63$ and $27.48 \mathrm{wt} \%$ ) were characterized for their mechanical properties both as prepared and after treatment with boiling water for $2,4,6,8$ and $24 \mathrm{~h}$. Weights of the samples were found to increase to a saturation at about $8 \mathrm{~h}$ with boiling water treatment.

In keeping with the composite principle, the mechanical properties improved with fibre loading. However, the properties were relatively inferior when treated with boiling water for longer hours attributing to ingress of moisture by capillary action through the interface between the fibre and the resin matrix. Considering the rates of moisture absorption and correlating with the mechanical properties, it was observed that the deteriorating effects were predominant up to $4 \mathrm{~h}$ treatment with boiling water. Estimation of defect concentrations for $63.5 \mathrm{wt} \%$ of nascent fibre reinforced composites as well as those composites treated with boiling water for $24 \mathrm{~h}$ were $56.93 \%$ and $\mathbf{6 4 . 1 6 \%}$ respectively. Similarly, $27.48 \mathrm{wt} \%$ nascent fibre reinforced composites and those composites with boiling water treatment showed the estimation of defect concentrations of $39.94 \%$ and $50.55 \%$ respectively. SEM study of the fractured surfaces showed heavy fibre pull-out in the tensile zone whilst shear fracture of the fibre bundles was predominant at the compressive zone of the samples tested for flexural strength properties.
\end{abstract}

Keywords. Nascent glass fibre; vinylester resin; moisture effects; fibre pull-out.

\section{Introduction}

Over the past few decades, glass fibre reinforced resin composites have been well accepted as engineering materials for various corrosive, high strength/modulus, sub zero temperature applications. As a common feature of composites, prominent anisotropy in mechanical properties was observed, which has high fracture strength and stiffness along the fibre strengthening component. Yet its potentials are not fully realized due to moisture affecting the long-term life of composite properties. Preparing defect free composites are rather uncommon arising from their adopted processing techniques through which moisture penetration is quite common. Many workers (Drzal et al 1985; Gaur and Miller 1990) have focused their attention on the effect of hydrothermal aging on the mechanical properties of bulk composites, on the other hand some workers (Koenig and Emadipour 1985; Biro et al 1993) have studied to evaluate the effect of aging on interfacial shear strengths by means of single-fibre microcomposite tests. In all these investigations a general deterioration in properties was evident. Research conducted

\footnotetext{
*Author for correspondence
}

on moisture absorption by several workers (Grant and Bradley 1995; Lekatou et al 1997; Soutis and Turkmen 1997; Srivastava and Hogg 1998) indicated that water penetration into polymer matrix composites involves three mechanisms: (i) diffusion of water molecules into the matrix directly and to a much lesser extent, into the filler material, (ii) flow of water molecules along the fillermatrix interface, followed by diffusion into the bulk matrix, and (iii) transport of water through microcracks or other forms of microdamage, such as pores or small channels already present in the material or expanded by water. Harper et al (1987) investigated the effects of voids upon the hygral and mechanical properties of graphite/epoxy composites and their moisture conditioning experiments showed that both the rate and the equilibrium level of moisture absorption depended upon the void content. An increase in the water salinity lead to a decrease in the maximum water absorption and saturation time for immersed glass and carbon fibre reinforced epoxy composites, as well as glass fibre reinforced polyesters. It was clear that a resin like polyester showed great resistance to moisture absorption when properly bonded to the glass in a fabric laminate, but when equally well cured as a casting it swelled and ruptured (Eakin 1969). Strengths after $2 \mathrm{~h}$ boiling in water for many well-bonded 
Table 1. Effect of boiling water treatment on silane coated fibres.

\begin{tabular}{ccccc}
\hline $\begin{array}{l}\text { Boiling time } \\
(\mathrm{min})\end{array}$ & $\begin{array}{c}\text { Weight of fibre } \\
\text { before boiling } \\
(\mathrm{g})\end{array}$ & $\begin{array}{c}\text { Weight of fibre } \\
\text { after boiling } \\
(\mathrm{g})\end{array}$ & $\begin{array}{c}\text { Weight loss } \\
(\%)\end{array}$ & $\begin{array}{c}\text { Weight gain } \\
(\%)\end{array}$ \\
\hline 5 & 17.5671 & 17.5534 & 0.078 & - \\
10 & 15.6813 & 15.6604 & 0.133 & - \\
20 & 16.0475 & 16.0330 & 0.090 & - \\
40 & 15.9713 & 15.9490 & 0.140 & - \\
$60(1 \mathrm{~h})$ & 16.2952 & $16 \cdot 2980$ & - & 0.017 \\
$120(2 \mathrm{~h})$ & 15.8357 & 16.0060 & - & 1.075 \\
\hline
\end{tabular}

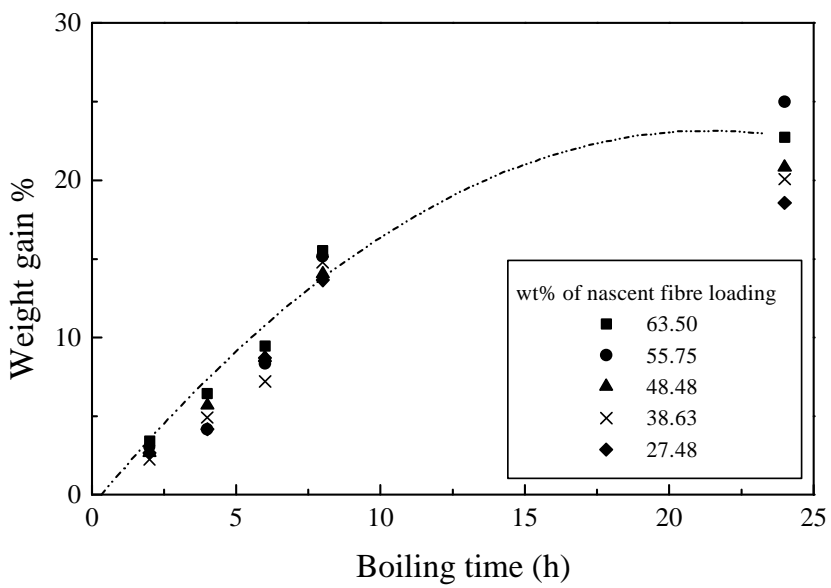

Figure 1. Weight gain $\%$ of the composites by the absorption of moisture after treatment with boiling water.

composites (Soutis and Turkmen 1997) were however, superior to dry strengths.

Rijsdijk et al (1993) experimented on the optimization and characterization of mechanical properties of unidirectional glass fibre reinforced polypropylene composites, including the effect of the interface on their properties. Their study showed an increase in composite strength due to superior bonding characteristics as a result of the addition of maleic-anhydride-modified polypropylene to continuous glass fibre reinforced polypropylene composites. Cheng et al (1993) studied a micromechanical behaviour of glass fibre adhesion to various types of resin including vinylester resin. They demonstrated that in case of the vinylester resin, which was expected to adhere to the fibres through an interpenetrating network mechanism, the maximum adhesion occurred after extractive hydrolysis removed much of the silane. The nominally uncoupled glass fibres were also found to adhere to the resins better than their coupled counterparts, as a result of the aminosilane combination. The functions of sizing agents and their interaction and reaction with fibres and fibre reinforced composites have also been reviewed by Ishida (1984) and Plueddemann (1988).

The effect of fibre content on the mechanical properties of glass-fibre reinforced plastics was reported by Lee and Jyongsik (1999), that as glass fibre content increased, the

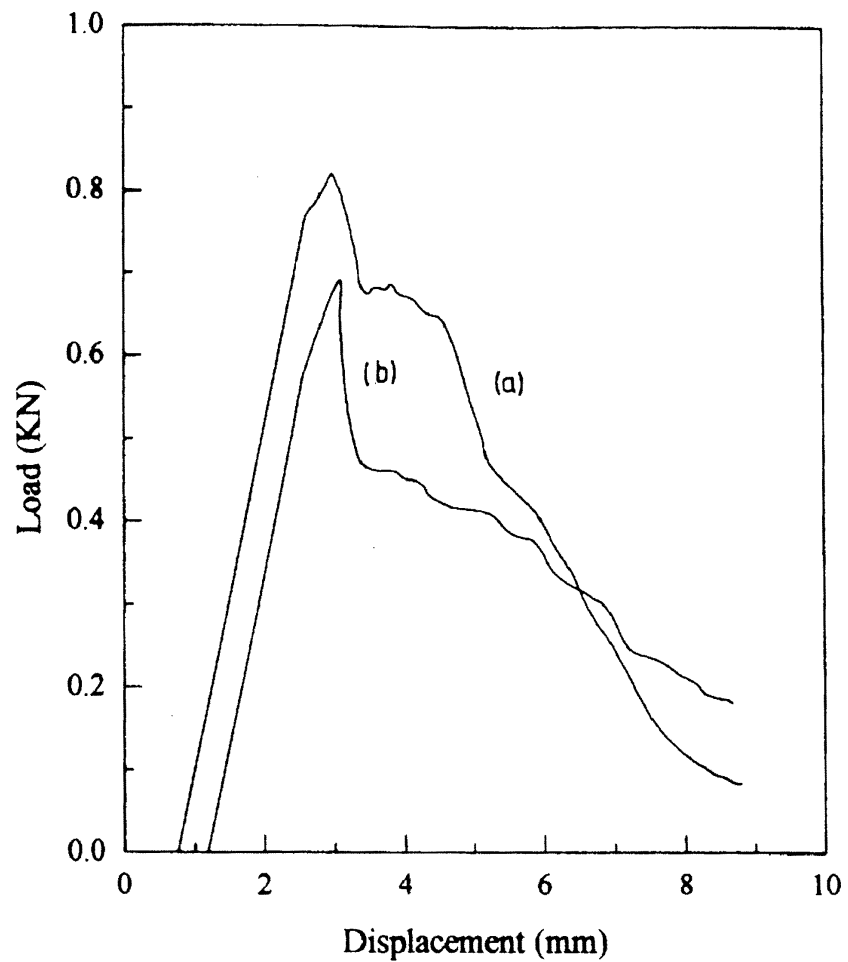

Figure 2. Load-displacement curves: (a) nascent fibre composite and (b) $8 \mathrm{~h}$ boiling water treated composite samples.

tensile and flexural modulus of the glass fibre composite showed a linear increment. Lin Ye (1992) discussed the basis for the characterization of interlaminar crack growth in composites and showed that the delamination was the most predominant and life limiting failure mechanism in composite. Sarkar (1998) had shown that greater the defect concentration, lower the strength properties of the composites and the strength properties are more affected by the defects in the fibre than in the matrix. Such defect concentration has an adverse effect on the overall behaviour of composites in moist environments. The environmental effect of moisture on fibre reinforced composite materials has thus remained of significant interest, particularly since mechanical and physical property modifications are generally manifested by its presence.

In this study, for an accelerated effect, the nascent glass fibre reinforced composites were boiled in distilled water 
for a duration of up to $24 \mathrm{~h}$. The effects of moisture on the mechanical properties of varying wt $\%$ of nascent fibre reinforced composites were determined. The changes in properties were analysed with the help of microstructures of the fractured surfaces.

\section{Experimental}

\subsection{Materials}

E-glass fibres having density of $2.56 \mathrm{~g} / \mathrm{cm}^{3}$ and modulus of $72.35 \mathrm{GPa}$ were used as reinforcing material in vinylester resin composites. The resin, a Bakellite Hylame product of grade HPR 8171 having density of $1.21 \mathrm{~g} / \mathrm{cm}^{3}$ and modulus of $2 \cdot 5-4 \mathrm{GPa}$, was used as the matrix mate- rial. Methyl ethyl ketone peroxide (MEKP), cobalt napthenate and $\mathrm{N}-\mathrm{N}$ dimethylaniline were used as catalyst, accelerator and promoter respectively.

\subsection{Composite processing}

Samples were prepared by E-glass fibre rovings soaked in vinylester resin with the catalyst, accelerator and promoter in $1: 1: 1$ ratio to the weight of the resin in the form of cylindrical glass tube of diameter $6 \mathrm{~mm}$. The soaked E-glass fibre rovings were pulled by hand through the cylindrical glass tube of $\sim 180 \mathrm{~mm}$ length and internal diameter $6 \mathrm{~mm}$. The pultruded samples within the glass tube were cured for $24 \mathrm{~h}$ at room temperature followed by post curing in an oven at $80^{\circ} \mathrm{C}$ for $4 \mathrm{~h}$. The glass tube

Table 2. Mechanical properties of composites prepared with nascent fibre and those treated with boiling water.

\begin{tabular}{|c|c|c|c|c|c|}
\hline $\begin{array}{l}\text { Wt\% of nascent } \\
\text { fibre }\end{array}$ & $\begin{array}{l}\text { Type of } \\
\text { composites }\end{array}$ & $\begin{array}{c}\text { Flexural } \\
\text { strength } \\
(\mathrm{MPa})\end{array}$ & $\begin{array}{l}\text { Modulus } \\
(\mathrm{GPa})\end{array}$ & $\begin{array}{l}\text { Breaking } \\
\text { energy }(\mathrm{J})\end{array}$ & $\begin{array}{c}\text { Toughness } \\
\left(\mathrm{kJ} / \mathrm{m}^{2}\right)\end{array}$ \\
\hline Vinylester resin & - & $120 \cdot 7$ & $2 \cdot 93$ & 0.4626 & $16 \cdot 37$ \\
\hline \multirow[t]{6}{*}{$27 \cdot 48$} & with nascent fibre & $444 \cdot 5$ & $11 \cdot 62$ & 0.5735 & $20 \cdot 29$ \\
\hline & treated for $2 \mathrm{~h}$ & $412 \cdot 7$ & $11 \cdot 06$ & 0.5315 & $18 \cdot 81$ \\
\hline & treated for $4 \mathrm{~h}$ & $399 \cdot 0$ & $11 \cdot 02$ & 0.5098 & $18 \cdot 04$ \\
\hline & treated for $6 \mathrm{~h}$ & $388 \cdot 9$ & $10 \cdot 76$ & $0 \cdot 4921$ & $17 \cdot 41$ \\
\hline & treated for $8 \mathrm{~h}$ & $374 \cdot 8$ & $10 \cdot 30$ & 0.4247 & $15 \cdot 03$ \\
\hline & treated for $24 \mathrm{~h}$ & $365 \cdot 9$ & $8 \cdot 70$ & $0 \cdot 3387$ & 11.99 \\
\hline \multirow[t]{6}{*}{38.63} & with nascent fibre & $475 \cdot 9$ & $14 \cdot 58$ & $0 \cdot 8224$ & $29 \cdot 10$ \\
\hline & treated for $2 \mathrm{~h}$ & $461 \cdot 2$ & $13 \cdot 97$ & $0 \cdot 8124$ & $28 \cdot 75$ \\
\hline & treated for $4 \mathrm{~h}$ & $452 \cdot 7$ & $13 \cdot 89$ & 0.7772 & $27 \cdot 50$ \\
\hline & treated for $6 \mathrm{~h}$ & $449 \cdot 2$ & $13 \cdot 58$ & 0.7225 & $25 \cdot 57$ \\
\hline & treated for $8 \mathrm{~h}$ & $437 \cdot 3$ & $12 \cdot 98$ & 0.6664 & $23 \cdot 58$ \\
\hline & treated for $24 \mathrm{~h}$ & $430 \cdot 5$ & $12 \cdot 05$ & $0 \cdot 6247$ & $22 \cdot 11$ \\
\hline \multirow[t]{6}{*}{$48 \cdot 48$} & with nascent fibre & $519 \cdot 9$ & $16 \cdot 70$ & 0.9653 & $34 \cdot 16$ \\
\hline & treated for $2 \mathrm{~h}$ & $508 \cdot 5$ & $16 \cdot 74$ & 0.9495 & $33 \cdot 60$ \\
\hline & treated for $4 \mathrm{~h}$ & $486 \cdot 9$ & $15 \cdot 58$ & 0.9504 & $33 \cdot 63$ \\
\hline & treated for $6 \mathrm{~h}$ & $470 \cdot 4$ & $14 \cdot 98$ & $0 \cdot 9045$ & $32 \cdot 00$ \\
\hline & treated for $8 \mathrm{~h}$ & $465 \cdot 7$ & $14 \cdot 71$ & $0 \cdot 8836$ & $31 \cdot 27$ \\
\hline & treated for $24 \mathrm{~h}$ & $463 \cdot 8$ & $14 \cdot 50$ & $0 \cdot 8448$ & $29 \cdot 90$ \\
\hline \multirow[t]{6}{*}{$55 \cdot 75$} & with nascent fibre & 554.9 & $19 \cdot 69$ & 1.0930 & $38 \cdot 79$ \\
\hline & treated for $2 \mathrm{~h}$ & $536 \cdot 0$ & $19 \cdot 27$ & $1 \cdot 0862$ & $38 \cdot 44$ \\
\hline & treated for $4 \mathrm{~h}$ & $527 \cdot 4$ & $18 \cdot 87$ & 1.0608 & $37 \cdot 54$ \\
\hline & treated for $6 \mathrm{~h}$ & $514 \cdot 3$ & $18 \cdot 18$ & $1 \cdot 0187$ & $36 \cdot 05$ \\
\hline & treated for $8 \mathrm{~h}$ & $503 \cdot 2$ & $17 \cdot 73$ & $1 \cdot 0004$ & $35 \cdot 40$ \\
\hline & treated for $24 \mathrm{~h}$ & $495 \cdot 8$ & $17 \cdot 36$ & 0.9947 & $35 \cdot 20$ \\
\hline \multirow[t]{6}{*}{$63 \cdot 50$} & with nascent fibre & $658 \cdot 9$ & $23 \cdot 78$ & 1.4268 & $49 \cdot 02$ \\
\hline & treated for $2 \mathrm{~h}$ & 623.9 & $22 \cdot 42$ & $1 \cdot 3654$ & $48 \cdot 32$ \\
\hline & treated for $4 \mathrm{~h}$ & $602 \cdot 8$ & $21 \cdot 35$ & $1 \cdot 2816$ & $45 \cdot 35$ \\
\hline & treated for $6 \mathrm{~h}$ & $581 \cdot 3$ & $21 \cdot 14$ & $1 \cdot 2012$ & $42 \cdot 50$ \\
\hline & treated for $8 \mathrm{~h}$ & $565 \cdot 5$ & $20 \cdot 43$ & $1 \cdot 1450$ & $40 \cdot 52$ \\
\hline & treated for $24 \mathrm{~h}$ & $548 \cdot 4$ & $20 \cdot 35$ & $1 \cdot 1112$ & $39 \cdot 32$ \\
\hline
\end{tabular}


jacket was then broken and separated from the composite samples. The weight of E-glass fibre rovings was measured by weighing the cut samples followed by burning off the resin at $550^{\circ} \mathrm{C}$. The residue glass was then weighed. The percentage of glass fibre were determined by

$$
\frac{\left(W_{1}-W\right)}{W_{1}} \times 100,
$$

where $W_{1}$ is the weight of the composite (fibre + resin) and $W$ the weight of resin. Composites with five different wt $\%(63.5,55 \cdot 75,48.48,38.63$ and $27.48 \mathrm{wt} \%)$ were prepared for the investigation.

\subsection{Test methods}

The silane coated nascent E-glass fibres were boiled in distilled water in a condenser flask for 5, 10, 20, 40, 60 and $120 \mathrm{~min}$. The composite samples with varying wt $\%$ of nascent fibres were similarly treated for $2,4,6,8$ and $24 \mathrm{~h}$. Vinylester resin in the form of rods were also treated in boiling water for $24 \mathrm{~h}$. Samples were then weighed in a digital balance for their weight gain. Composites prepared with varying wt\% of nascent fibres and also the prepared composites treated with boiling water were tested for their flexural strength, modulus and toughness under three-point bend tests in an INSTRON 4303 universal testing machine in accordance with ASTM D790M-81.

\section{Results and discussion}

The nascent fibres on treating with boiling water however lost weight, as shown in table 1 , due to the removal of silane coating during the first $40 \mathrm{~min}$ of treatment. The bare fibres thus becoming exposed gained weight very rapidly by absorbing moisture and by $120 \mathrm{~min}$ the gain

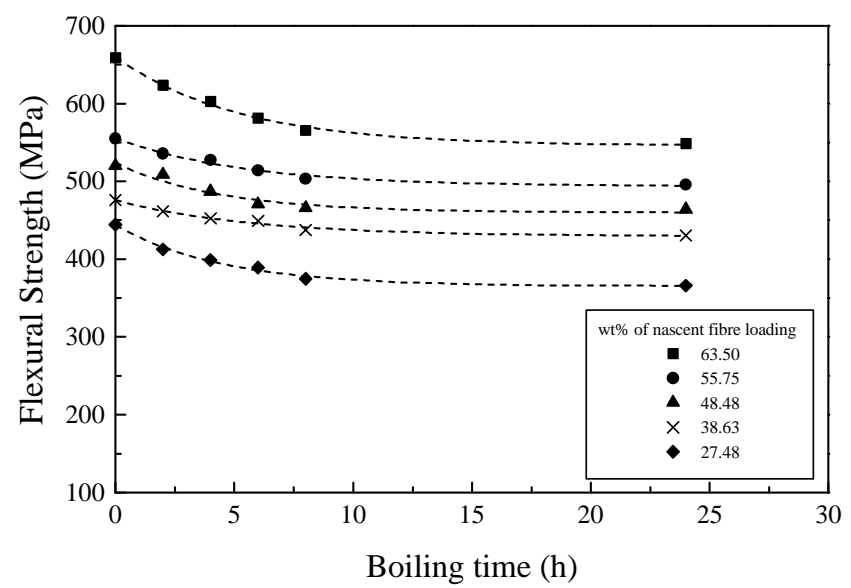

Figure 3. The strength degradation of nascent fibre reinforced composites after treatment with boiling water. was $1.075 \%$. The vinylester resin samples did not show any gain in weight after treatment in boiling water for $24 \mathrm{~h}$. Weight gained by the composite samples with boiling time by the absorption of moisture is shown in figure 1 . A sharp gain in all wt\% of nascent fibre reinforced composite samples was seen to occur with boiling time till $8 \mathrm{~h}$. Thereafter, the gain had been rather shallow. A maximum gain of about $17-25 \%$ was measured and absorption was greater for higher fibre reinforced composites. A parabolic relationship of the kind $X_{\mathrm{o}}=k t^{n}$ was evident, where $X_{\mathrm{o}}$ is the total moisture absorbed in time $t, k$ the constant and $n$ the slope having a value of $1 \cdot 11$.

It is assumed that the moisture proceeded by the inward movements due to concentration gradient between the ends and its centre of the composite samples, slowly reacting with the silane coating detaching it from the glass fibre surface allowing further penetration. The flux of the moisture across the glass-matrix interface can be assumed to be obeying Fick's law when,

$$
F=-D_{\text {eff }}\left(C_{\mathrm{o}}-C_{\mathrm{i}}\right) / X_{\mathrm{o}},
$$

where $F$ is the flux of moisture molecules crossing a unit surface area in a unit time, $C_{\mathrm{o}}$ the concentration of moisture available for reaction at a given time, $C_{\mathrm{i}}$ the concentration of moisture at the reacting interface and $D_{\text {eff }}$ the effective diffusion coefficient.

An operative phenomenon of this kind is borne out from the fact that the composite samples with increasing fibre loading had more gain in weight having larger glass surface area for the reaction and consequent fall in properties.

The set of mechanical properties of the composites prepared with varying wt $\%$ of nascent fibres and those composites treated with boiling water for a duration of up to $24 \mathrm{~h}$ is given in table 2 . The load-displacement behaviour of (a) composite having $63.5 \mathrm{wt} \%$ of nascent fibre and (b) $63.5 \mathrm{wt} \%$ nascent fibre reinforced composite sample treated with boiling water for $8 \mathrm{~h}$ is shown in

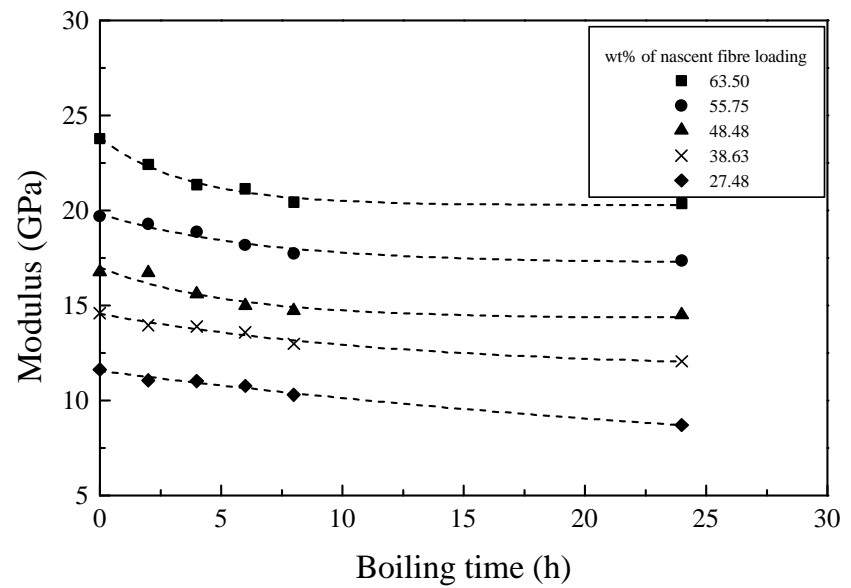

Figure 4. The degradation of modulus of nascent fibre reinforced composites after treatment with boiling water. 
figure 2. The figure shows a few distinct features. The nascent fibre reinforced composite sample displayed a continuous rise in load with displacement until the peak load was reached where a deflection was noticed. It could be the start of the debonding of the interface followed by a sudden drop in load to $0.68 \mathrm{kN}$. At this static load, displacement occurred by 2 units indicating fibre breakage and matrix cracking followed by a continuous drop in load as broken fibres gave way. The treated composite sample on the other hand had a similar pattern but for the sudden drop in load to $0.46 \mathrm{kN}$ and a gradual drop. The initial debonding effect to the peak load was relatively larger. The flexural strength, modulus and toughness values of composites with varying wt $\%$ of reinforcement of nascent fibre were plotted against boiling time, shown in figures 3, 4 and 5 respectively. It was observed that there had been an initial drop in the properties up to $8 \mathrm{~h}$ of boiling water treatment of the composites, thereafter remaining relatively unchanged in keeping with the gain in weight by moisture absorption. When the $63.5 \mathrm{wt} \%$ and $27.48 \mathrm{wt} \%$ of nascent fibre reinforced composites were given a boiling treatment of $8 \mathrm{~h}$ having absorbed $15.53 \%$ and $13.64 \%$ moisture respectively; the flexural strength and toughness of the $63.5 \mathrm{wt} \%$ of nascent fibre reinforced composites had dropped by $14.2 \%$ and $17.3 \%$ respectively whereas for $27.48 \mathrm{wt} \%$ of nascent fibre reinforced composites the flexural strength and toughness had dropped by $15.7 \%$ and $26 \%$ respectively. The modulus however, remained relatively unchanged. The nature of deterioration in properties was similar for all the different wt $\%$ of nascent fibre reinforced composites.

From the moisture absorption characteristics of the fibre shown in table 1, it was seen that a two-way mechanism operated for the deterioration of the composite properties on boiling, i.e. (i) dissolution of silane starting from the open edges of the composite samples, creating debonding at the interface and (ii) the moisture further penetrated through the gap by capillary action and the

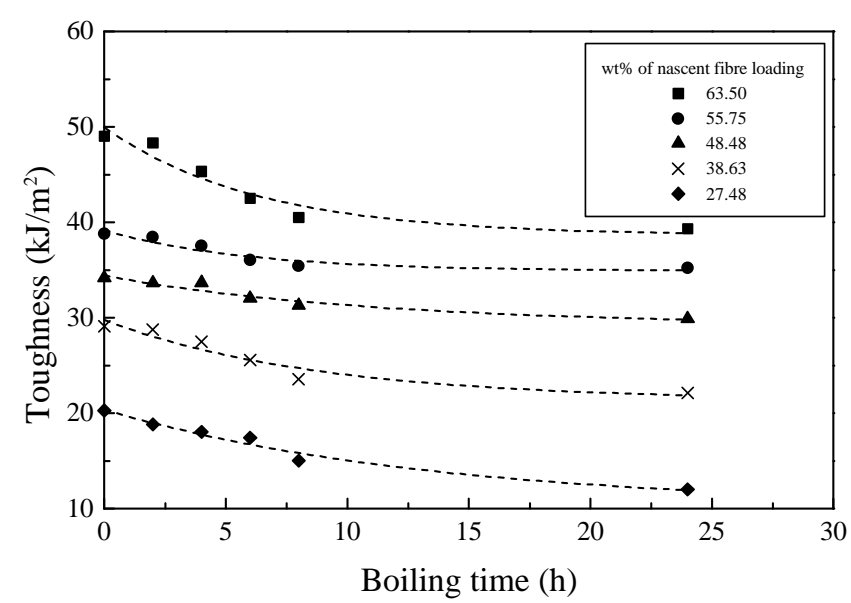

Figure 5. The degradation of toughness of nascent fibre reinforced composites after treatment with boiling water. fibres absorbing the moisture simultaneously to a saturation point in agreement with the observations made by Grant and Bradley (1995), and Srivastava and Hogg (1998). The weight gain of the composite samples due to boiling water treatment could only be possible by the ingress of moisture through the interface between the silane coated glass reinforcing fibres and the polymer matrix. Since both the coated glass fibres and the cured vinylester matrix are inactive to moisture, the silane is the only species available for the reaction with moisture. The isolated pores in the matrix cannot be a part of the weight gain by moisture absorption.

The rate of change $(R)$ in the flexural strength, modulus and toughness of the nascent fibre reinforced composite samples boiled from 2 to $24 \mathrm{~h}$ are shown in figures 6,7 and 8 respectively. The rate of change depicting the effect of water on the composites occurred linearly with increased wt $\%$ of the fibre content, the effect being maxi-

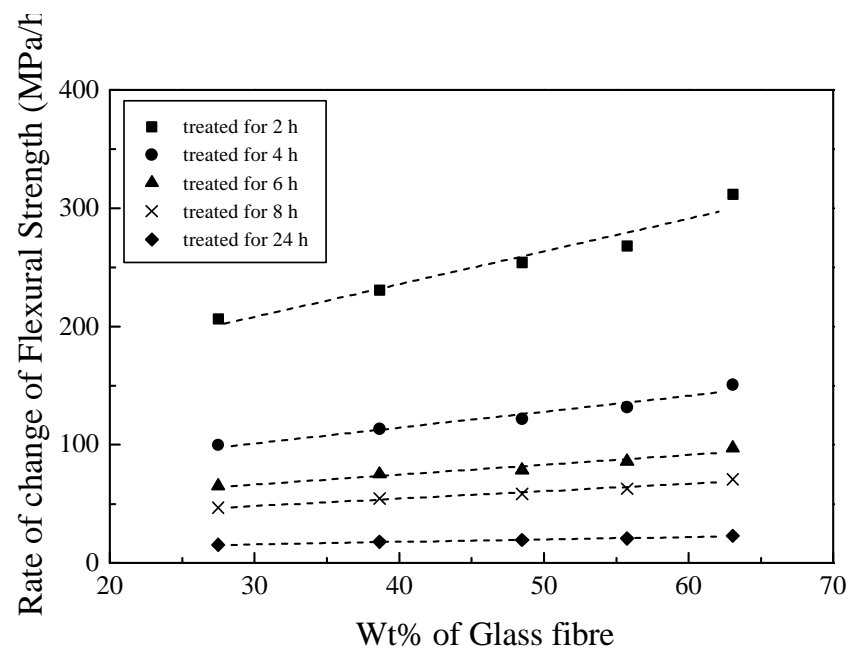

Figure 6. The rate of change of strength of boiling water treated nascent fibre reinforced composites.

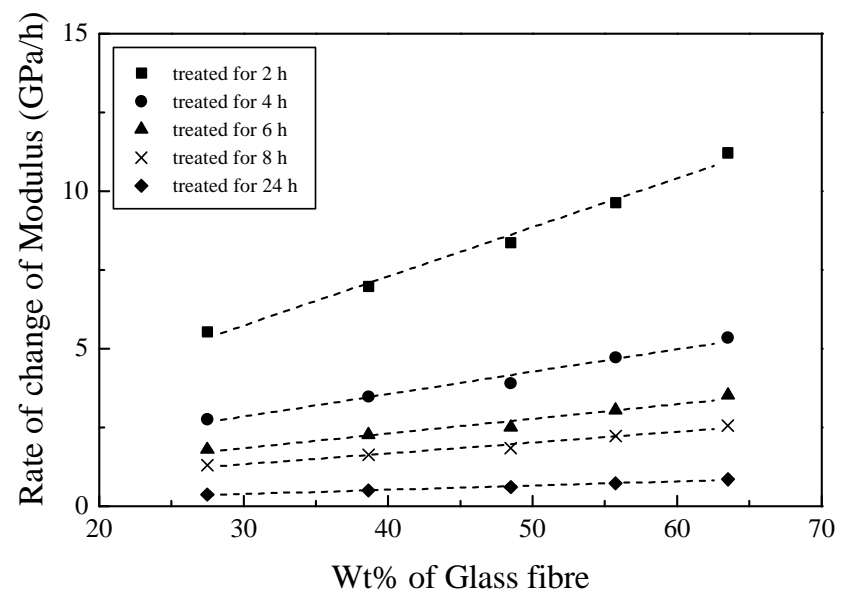

Figure 7. The rate of change of modulus of boiling water treated nascent fibre reinforced composites. 
mum for nascent fibre reinforced composites ( $4 \mathrm{~h}$ treated in boiling water for all wt\%). The rate dropped off at longer boiling time. This could be expressed as

$$
R=P \cdot W_{\mathrm{f}}+C,
$$

where $R$ is the rate of change of composite properties, $P$ the slope and $W_{\mathrm{f}}$ the wt $\%$ of fibre reinforcement and $C$ the constant. Taking the different slopes of ' $P$ ' from figures 6 and 7, for flexural strength and modulus respectively, a plot of ' $P$ ' against boiling time is depicted in figure 9. A sharp decrease in properties was noticed till $8 \mathrm{~h}$ of boiling treatment in water when moisture concentrations in the samples were maximum. It is indicative that the mechanical properties depended upon the volume of moisture intake in the samples. As the saturation approached the moisture ingress diminished, and the rate dropped.

However, the results described earlier also reflect the presence of defects in the samples, their concentration in the samples were determined by comparing the actual strengths with the theoretical strengths, estimated from the rule of mixtures. The variation of strength properties of

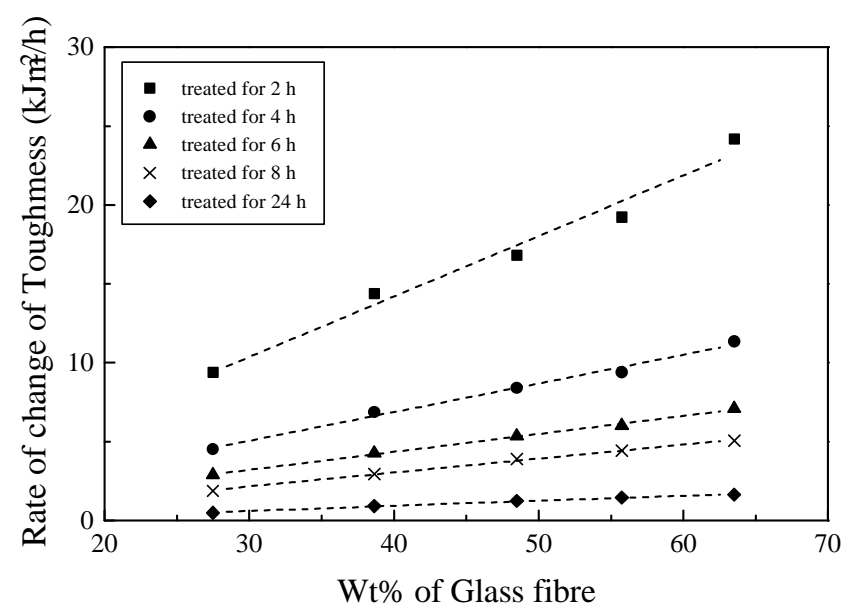

Figure 8. The rate of change of toughness of boiling water treated nascent fibre reinforced composites.

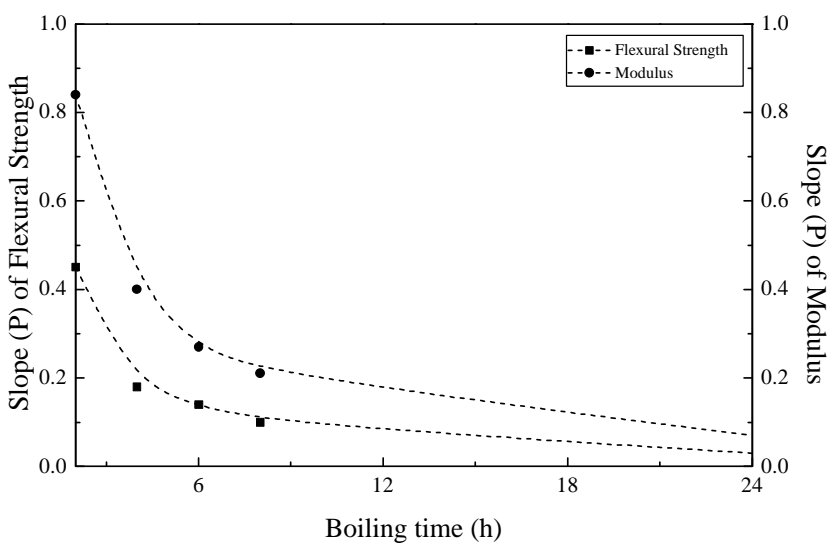

Figure 9. The variation of slope $(P)$ of strength and modulus of boiling water treated nascent fibre reinforced composites. composites with wt\% of nascent fibre reinforcement is shown in figure 10 . Whilst the improvements in properties with increasing wt $\%$ of nascent fibres occurred but a large difference between the estimated and actually measured values was observed. The observed percentages of defect concentrations in the estimated and measured values of nascent fibre reinforced composites and nascent fibre reinforced composites treated with boiling water are plotted against the wt $\%$ of nascent fibre reinforcement shown in figure 11. It showed that for $63.5 \mathrm{wt} \%$ and $27.48 \mathrm{wt} \%$, nascent fibre reinforced composites had defects of $56.93 \%$ and $39.94 \%$ respectively. These composites when treated for $24 \mathrm{~h}$ in boiling water had $64.16 \%$ and $50.55 \%$ defects respectively. By using the model proposed by Sarkar (1998) on the strengths of composites with defect concentration as,

$$
\sigma_{\mathrm{c}}=V_{\mathrm{f}}\left(n_{1} e^{-k d_{1}}-n_{2} e^{-k d_{2}}\right)+n_{2} e^{-k d_{2}},
$$

where, $\sigma_{\mathrm{c}}$ is the composite strength, $V_{\mathrm{f}}$ the volume $\%$ of fibre, $n_{1}, n_{2}$ are fibre and matrix strengths at the defect

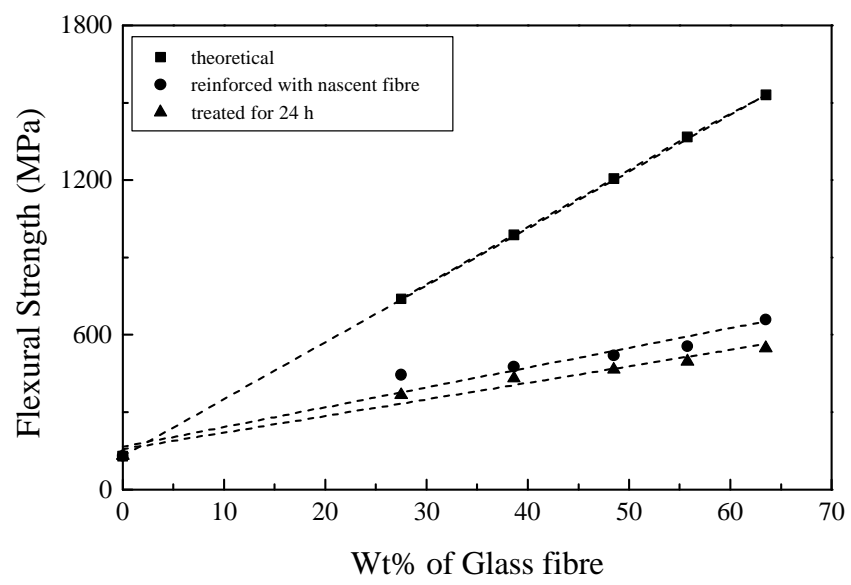

Figure 10. The variation of strength properties of composites.

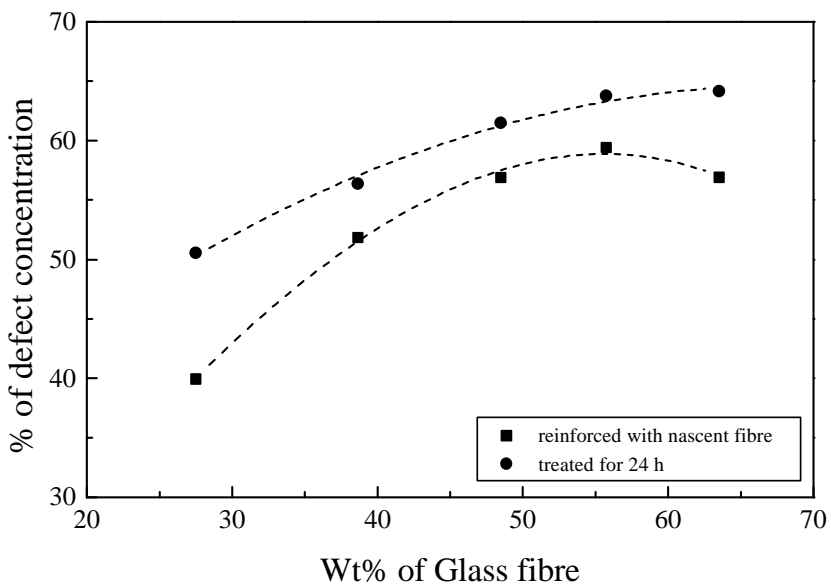

Figure 11. The percentage of defects concentration of composites. 


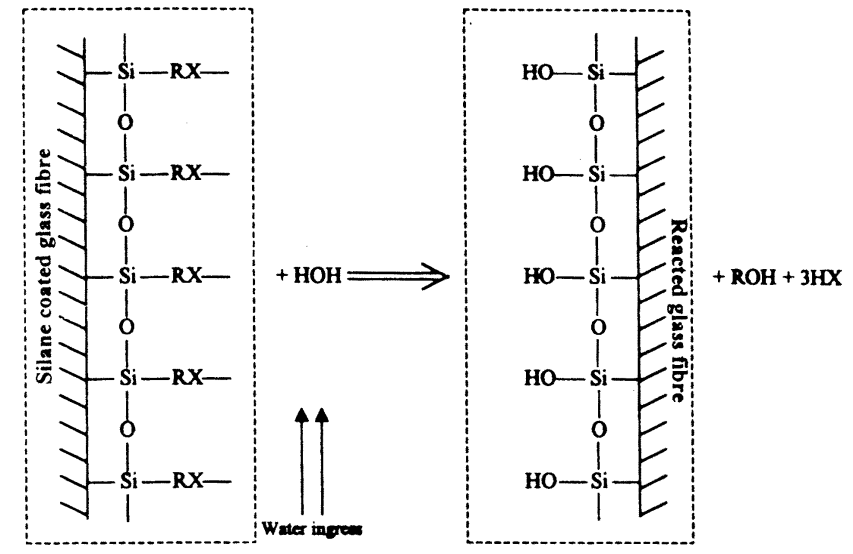

Figure 12. Schematic representation of the hydrolysis of silane $(\mathrm{RX})$ coating on the glass fibre by water ingress through the interface.

concentrations of $d_{1}$ and $d_{2}$ respectively and $k$ a constant, the percentage of defects in the above two composites with $63.5 \mathrm{wt} \%$ and $27.48 \mathrm{wt} \%$ of nascent fibre reinforcement, considering no defects in the fibres were estimated to be $53 \%$ and $39 \%$ showing a close proximity between the experimental and estimated values. The ingress of water through the interface by the hydrolysis of silane coating of the fibres at the interface (table 1), is shown schematically in figure 12 , that might have caused the debonding to expand, thereby, increasing the defect concentration under the treatment with boiled water resulting into the gain in weight of the composites. In accordance with the concept of rule of mixtures the properties improved with increasing fibre loading (Lee and Jyongsik 1999) for both the cases, i.e. composites having nascent fibre and those composites treated with boiling water.

The fractured surfaces of the composites were examined under SEM. It was observed that the fibre breakage and pull-out had been predominant for the composites having nascent fibres and those treated with boiling water. At the tension zone heavy fibre pull-out with matrix cracking and debonding were prevalent. Shear fracture of fibres occurred at the compressive zones of the composites reinforced with nascent fibres and those composites treated with boiling water, shown in figures $13 \mathrm{a}$ and $\mathrm{b}$ respectively. Both debonding and matrix cracking were visible. The cracks predominantly originated from debond and propagated into the matrix having the debonded cracks joined into continuous cracks. Thus weakening the composites further as revealed in figure 2 , where the continuous drop in load was observed.

\section{Conclusions}

The volume of moisture absorbed by the samples increased with boiling time to a saturation after $8 \mathrm{~h}$ of treatment
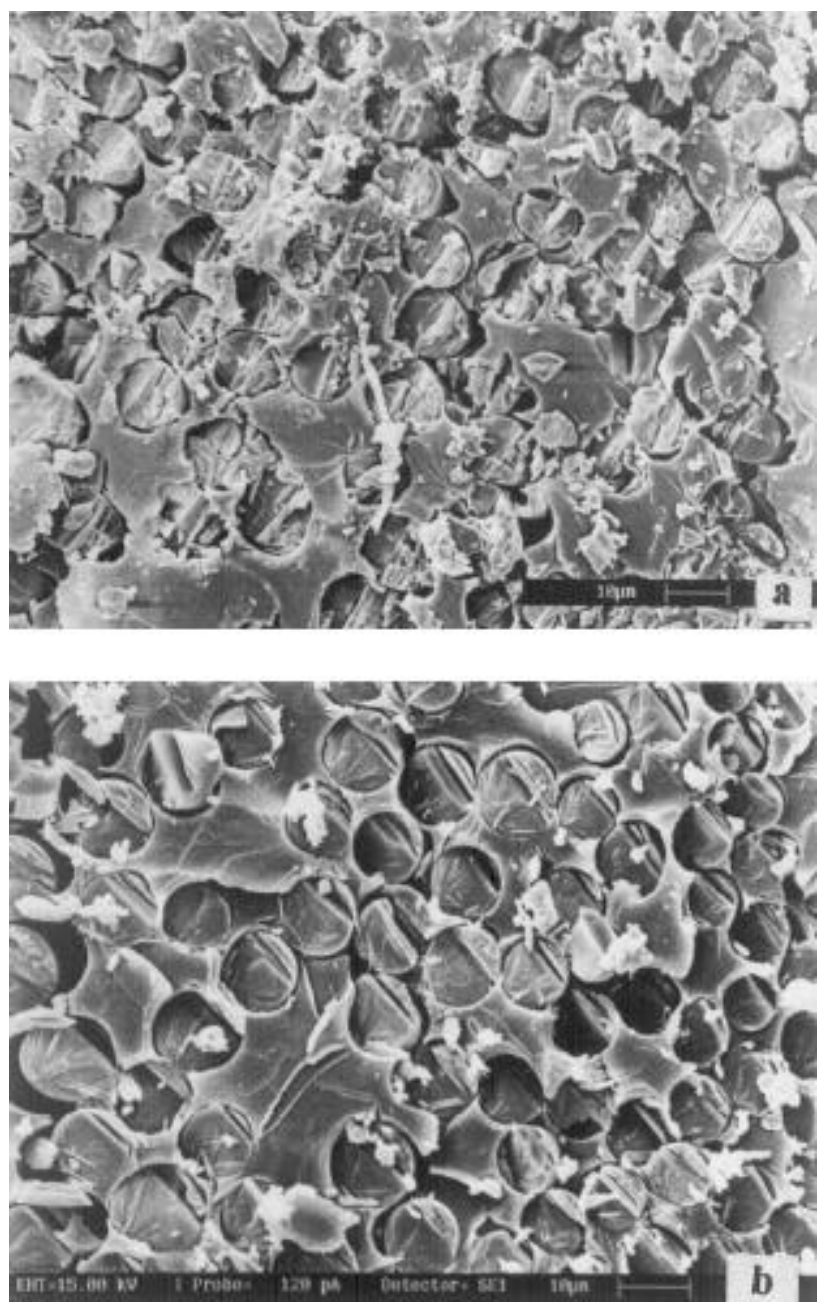

Figure 13. Shear fracture of the fibres at the compressive zone of composite a. nascent fibre reinforced and b. treated with boiling water for $8 \mathrm{~h}$.

with boiled water. The rate at which the moisture was absorbed was maximum at lower boiling times and had slowed down at longer duration of boiling. However, for longer duration of exposure the fibres were also affected seriously. The differences in properties between the composites having nascent fibre and nascent fibre composites treated with boiling water at varying amounts of fibre loading were not much except for the larger wt $\%$ of fibre reinforcement, indicating the effect of moisture to be more pronounced at such larger fibre reinforcement. The role of higher wt $\%$ of fibre reinforcement in the composites has been more predominant in retaining its superior properties although they absorbed larger quantities of moisture thus increasing the defect concentrations. The moisture ingress had been through the interface by the hydrolysis of silane coating on fibres leaving voids at the interface.

The fractured surfaces revealed heavy debonded surfaces between the reinforcement and the matrix, particularly 
for samples given boiling treatment. The debonded areas joined to form continuous long cracks weakening the composites. The presence of such defects affecting the properties were apparent that matched with the estimated amounts.

\section{Acknowledgements}

The authors are indebted to the Council of Scientific and Industrial Research, New Delhi, for providing financial assistance during the course of investigation. Sincere thanks are due to Mr A K Rana and Mrs M Sarkar, Indian Jute Industries Research Association, for their help with the Instron facilities. Mr S K Dalui, Mr K Banerjee and Ms A Saha are also acknowledged for their help in sample preparation, testing and measurements. The Director General of GSI and Dr S Shome in particular are acknowledged for their help with the SEM facility. The Director, Indian Association for the Cultivation of Science, is acknowledged for the infrastructural facilities.

\section{References}

Biro D A, Pleizier G and Deslandes Y 1993 Comp. Sci. \& Technol. 46293
Cheng T H, Jones F R and Wang D 1993 Comp. Sci. \& Technol. 4889

Drzal L T, Rich M T and Koenig M F 1985 J. Adhesion 18 49

Eakin W J 1969 ASTM STP-452 (Philadelphia PA: American Society for Testing and Materials) p. 137

Gaur U and Miller B 1990 Polym. Comp. 11217

Grant T S and Bradley W L 1995 J. Comp. Mater. 29852

Harper B D, Staab G H and Chen R S 1987 J. Comp. Mater. 21 280

Ishida H 1984 Polym. Comp. 5101

Koenig J L and Emadipour H 1985 Polym. Comp. 6142

Lee Nam-Jeong and Jyongsik Jang 1999 Composites 30815

Lekatou A, Faidi S E, Ghidaoui S B, Lyon S B and Newmen R C 1997 Composites A28 223

Lin Ye 1992 Comp. Sci. \& Technol. 4349

Plueddemann E P 1988 Silane coupling agents (New York: Plenum)

Rijsdijk H A, Contant M and Peijs A A J M 1993 Comp. Sci. \& Technol. 48161

Sarkar B K 1998 Bull. Mater. Sci. 21329

Soutis C and Turkmen D 1997 J. Comp. Mater. 31832

Srivastava V K and Hogg P J 1998 J. Mater. Sci. 33 1129 